\title{
Breeding of transgenic cattle for human coagulation factor IX by a combination of lentiviral system and cloning
}

\author{
P.S. Monzani ${ }^{1,3}$, J.R. Sangalli ${ }^{1}$, T.H.C. De Bem ${ }^{1,4}$, F.F. Bressan ${ }^{1}$, \\ P. Fantinato-Neto ${ }^{1}$, J.R.V. Pimentel ${ }^{1}$, E.H. Birgel-Junior ${ }^{1}$, \\ A.M. Fontes ${ }^{2}$, D.T. Covas ${ }^{2}$ and F.V. Meirelles ${ }^{1}$ \\ ${ }^{1}$ Departamento de Ciências Básicas, \\ Faculdade de Zootecnia e Engenharia de Alimentos, \\ Universidade de São Paulo, Pirassununga, SP, Brasil \\ ${ }^{2}$ Hemocentro, Universidade de São Paulo, Ribeirão Preto, SP, Brasil \\ ${ }^{3}$ Central Avançada em Biotecnologia da Reprodução Animal, \\ Universidade Norte do Paraná, Londrina, PR, Brasil \\ ${ }^{4}$ Departamento de Genética, Faculdade de Medicina de Ribeirão Preto, \\ Universidade de São Paulo, Ribeirão Preto, SP, Brasil \\ Corresponding author: P.S. Monzani \\ E-mail: monzani.paulo@gmail.com
}

Genet. Mol. Res. 12 (3): 3675-3688 (2013)

Received July 18, 2012

Accepted November 22, 2012

Published February 28, 2013

DOI http://dx.doi.org/10.4238/2013.February.28.25

\begin{abstract}
Recombinant coagulation factor IX must be produced in mammalian cells because FIX synthesis involves translational modifications. Human cell culture-based expression of human coagulation factor IX (hFIX) is expensive, and large-scale production capacity is limited. Transgenic animals may greatly increase the yield of therapeutic proteins and reduce costs. In this study, we used a lentiviral system to obtain transgenic cells and somatic cell nuclear transfer (SCNT) to produce transgenic animals. Lentiviral vectors carrying hFIX driven by 3 bovine $\beta$-casein promoters were constructed. Bovine epithelial mammary cells were transduced by lentivirus, selected with blasticidin, plated on extracellular matrix, and
\end{abstract}


induced by lactogenic hormones; promoter activity was evaluated by quantitative PCR. Transcriptional activity of the $5.335-\mathrm{kb}$ promoter was 6-fold higher than the 3.392- and 4.279-kb promoters, which did not significantly differ. Transgenic bovine fibroblasts were transduced with lentivirus carrying the $5.335-\mathrm{kb}$ promoter and used as donor cells for SCNT. Cloned transgenic embryo production yielded development rates of $28.4 \%$, similar to previous reports on cloned non-transgenic embryos. The embryos were transferred to recipient cows $(\mathrm{N}=21)$ and 2 births of cloned transgenic cattle were obtained. These results suggest combination of the lentiviral system and cloning may be a good strategy for production of transgenic cattle.

Key words: Human coagulation factor IX; Transgenic cloned cattle; Mammary epithelial cells; $\beta$-casein promoter; Hemophilia

\section{INTRODUCTION}

The production of recombinant proteins is one of the major achievements of biotechnology; animal cells are required to synthesize proteins with the appropriate post-translational modifications (Houdebine, 2000). Efficient host-cell expression of coagulation factors is hampered by the need for specific post-translational modifications. Production of recombinant factor IX (rFIX) requires the use of mammalian cells because FIX synthesis involves glycosylation, $\gamma$-carboxylation, $\beta$-hydroxylation, sulfation, phosphorylation, and $N$-terminus processing (Suttie, 1980; Kurachi and Davie, 1982; Fernlund and Stenflo, 1983). The first rFIX approved for treatment of hemophilia B (BeneFix; Pfizer) was expressed in Chinese hamster ovary cells (Balland et al., 1988). The post-translational modifications of this rFIX are similar but not identical to those in plasma-derived FIX (Bond et al., 1998); however, the early rFIX showed similar clotting activities (White et al., 1997). Although recombinant proteins reduce demand for blood and blood products, their production capacity is limited. Eighty percent of the world's population does not have access to hemophilia therapeutics (Bishop and Lawson, 2004), due to the high cost of recombinant proteins and the inability of production to meet global demand. The production of therapeutic proteins from transgenic animals is an alternative technique to address these issues (Bishop and Lawson, 2004).

Milk, egg white, blood, urine, seminal plasma, and silkworm cocoons from transgenic animals are candidate sources of industrial-scale recombinant protein production (Houdebine, 2000). The mammary gland is preferred, mainly because of the quantities of protein that can be produced by employing various mammary gland-specific promoters and the ease of production and purification (Rudolph, 1999). The importance of the mammary gland as bioreactor to produce recombinant protein has been reviewed (Niemann and Kues, 2007; Houdebine, 2009); 2 products derived from the milk of transgenic animals have been approved and are being commercialized - antithrombin- $\alpha$ (ATryn, GTC BioTherapeutics, UK) and C1 esterase inhibitor (RUCONEST, Pharming Group N.V.).

Production of human recombinant proteins in the milk of transgenic animals varies from a few micrograms per liter to grams to, in some cases, more than $20 \mathrm{~g} / \mathrm{L}$. Different promoters have been used for the specific expression of recombinant protein in milk, including 
$\alpha_{\mathrm{S} 1}$-casein, $\beta$-casein, $\beta$-lactoglobulin, $\alpha$-lactalbumin, and whey acidic protein. The $\beta$-casein gene promoter contains several transcription factor-binding sites. A $\beta$-casein enhancer element, located in the distal bovine promoter between -1562 and -1613 , contains binding sites for Stat5, c/ebp, YY1, and GR (Raught et al., 1995).

The length of the $\beta$-casein promoter can be optimized for efficient recombinant protein expression. Human thrombopoietin (Sohn et al., 1999) and human interleukin-10 (Sohn et al., 2003) were expressed from a 10-kb bovine $\beta$-casein gene promoter in the milk of transgenic mice. Human growth hormone expression in milk was driven by a $3.8-\mathrm{kb}$ promoter of mice (Cerdan et al., 1998). Human type II collagen was expressed from 1.8- and 3.1-kb bovine $\beta$-casein promoters in transgenic mice (Naruse et al., 2006). A 3.7-kb promoter fragment was used to express human follicle-stimulating hormone in transgenic mice (Kim et al., 2007). The reporter gene chloramphenicol acetyl transferase was expressed in transgenic bovine mammary epithelial cells (BMECs) from a 950-bp promoter fragment (Ahn et al., 1995). Others have proposed that 3.1- (Naruse et al., 2006) and 3.8-kb (Cerdan et al., 1998) promoters are sufficient for the production of transgenic animals.

Most studies of recombinant protein expression from $\beta$-casein promoters of varying lengths have been evaluated in the milk of transgenic animals. However, BMEC cultured on extracellular matrix is an alternative approach to reproduce mammary gland biology (Rose and McConochie, 2006), and we believed it would be a suitable model system for the evaluation of cells and gene constructs to be used in the generation of transgenic animals that produce recombinant proteins in milk.

In this study, lentiviral expression vectors containing human coagulation factor IX (hFIX) cDNA driven by 3 different bovine $\beta$-casein promoters were used to transduce BMECs. Transgenic cells provided a model for the analysis of exogenous gene expression from these vectors. Bovine fibroblasts were transduced with lentivirus carrying the best construct and used in somatic cell nuclear transfer (SCNT) to produce transgenic bovine embryos, which were transferred to recipients and yielded transgenic animal births.

\section{MATERIAL AND METHODS}

\section{Cloning of the $\beta$-casein promoter regions and hFIX cDNA}

A 5.335-kb upstream sequence containing the distal enhancer elements, promoter, and 5 '-untranslated region (UTR) (consisting of $43 \mathrm{bp}$ of the first exon and $218 \mathrm{bp}$ of the first intron) of the $\beta$-casein gene (P $\beta$ cas5) was obtained from the bovine genome (Monzani et al., 2011). Based on this sequence, primers were designed to amplify additional DNA fragments of 4.279 $\mathrm{kb}(\mathrm{P} \beta$ cas 4$)$ and $3.392 \mathrm{~kb}(\mathrm{P} \beta \operatorname{cas} 3)$ (Table 1). Amplification of $\mathrm{P} \beta$ cas 4 and $\mathrm{P} \beta$ cas 3 was performed with recombinant Taq DNA polymerase and the following cycling parameters: 3 min at $94^{\circ} \mathrm{C} ; 35$ cycles of $45 \mathrm{~s}$ at $94^{\circ} \mathrm{C}, 30 \mathrm{~s}$ at $55^{\circ} \mathrm{C}, 3 \mathrm{~min}$ at $72^{\circ} \mathrm{C}$; and a final 10 -min elongation step at $72^{\circ} \mathrm{C}$. Amplification products were recovered from a $1 \%$ agarose gel, cloned into pGEM-T Easy (Promega), and transformed into Escherichia coli $\mathrm{DH} 5 \alpha \mathrm{CaCl}_{2}$-competent cells. Transformant colonies were selected on the chromogenic substrate X-gal. The fragment P $\beta$ cas5, constructed in pT7-blue3 (Novagen), was partially sequenced (proximal to the promoter) to confirm the $\beta$-casein promoter cloning, which involved 25 cycles of PCR amplification of $10-\mu \mathrm{L}$ reaction volumes containing 200 ng plasmid DNA, $10 \mathrm{pM}$ primer T7 (Novagen), and $4 \mu \mathrm{L}$ ET Dye Ter- 
minator (GE Healthcare). The sequencing reactions were ethanol-precipitated and the pellets resuspended in $3.5 \mu \mathrm{L}$ loading buffer; $1.5 \mu \mathrm{L}$ was loaded onto a sequencing gel and data were collected by an ABI PRISM 377 DNA Sequencer (Perkin Elmer, Applied Biosystems). The $\mathrm{P} \beta$ cas 4 and $\mathrm{P} \beta$ cas 3 fragments were amplified from $\mathrm{pT} 7$-blue-P $\beta$ cas 5 with primers $\mathrm{P} 1$ and $\mathrm{P} 2$, and $\mathrm{P} 3$ and P2, respectively. The human coagulation FIX cDNA (1.386 kb) was amplified from pLXIN-hFIX, kindly provided by Dr. A.M.F., with primers P4 and P5 and the following cycling conditions: $3 \mathrm{~min}$ at $94^{\circ} \mathrm{C} ; 35$ cycles of $45 \mathrm{~s}$ at $94^{\circ} \mathrm{C}, 30 \mathrm{~s}$ at $55^{\circ} \mathrm{C}, 1.5 \mathrm{~min}$ at $72^{\circ} \mathrm{C}$; and a final 10 -min elongation step at $72^{\circ} \mathrm{C}$. The amplification product was cloned into pGEM-T Easy. All constructs were confirmed by PCR and restriction mapping.

\begin{tabular}{lll}
\multicolumn{2}{l}{ Table 1. Sequence primers used for construction vectors (Monzani et al., 2011). } & \\
\hline Primer & Sequence & Restriction site \\
\hline P1 - FWD & 5'-ATCGATGCATTGGAGAAGG-3' & ClaI \\
P2 - REV & 5'-GGATCCGTTAACTAGTCTCGTG-3' & BamHI \\
P3 - FWD & 5'-ATCGATGCCACCTAATGCGAAGATCTGACTC-3' & ClaI \\
P4 - FWD & 5'-GGATCCATGCAGCGCGTGAACATGATC-3' & BamHI \\
P5 - REV & 5'-CCCTCGAGTTAGGTGAGCTTGTTTTTCC-3' & XhoI \\
\hline
\end{tabular}

The sequences in italics correspond to the restriction site contained in the primer.

\section{Construction of mammary gland-specific expression vectors}

The lentiviral vector pLenti6.2-GW/EmGFP (7.833 kb, Invitrogen) was used to construct 3 expression vectors. Initially, pLenti6.2-GW/EmGFP was cleaved with ClaI and BamHI to remove the $\mathrm{P}_{\mathrm{CMV}}$ promoter and pT7-blue3-P $\beta$ cas5, pGEM-P $\beta$ cas4, and pGEM$\mathrm{P} \beta$ cas 3 were cleaved with same enzymes to obtain $\beta$-casein promoter cassettes. The cleavage products were recovered and incubated with $\mathrm{T} 4 \mathrm{DNA}$ ligase overnight at $4{ }^{\circ} \mathrm{C}$, producing pLenti-P $\beta$ cas5-EmGFP, pLenti-P $\beta$ cas4-EmGFP, and pLenti-P $\beta$ cas3-EmGFP. Next, these vectors, together with pGEM-hFIX, were cleaved with BamHI and XhoI. In this step, the EmGFP gene was excised and hFIX cDNA was introduced, producing the expression vectors pLenti-P $\beta$ cas5-hFIX, pLenti-P $\beta$ cas4-hFIX, and pLenti-P $\beta$ cas3-hFIX. These vectors were used for $E$. coli transformation and later purified. The constructs were confirmed by restriction mapping and used for lentivirus production.

\section{Lentivirus production}

Lentivirus production was performed by lipofection of 293FT cells (Invitrogen) with pLP1, pLP2, and pLP/VSV-G (ViraPower Lentiviral Packaging Mix, Invitrogen), as well as the expression constructs, according to manufacturer instructions. After $48 \mathrm{~h}$ of transfection, the culture media were filtered with PVDF syringe filters $(0.45 \mu \mathrm{M}$, Millipore $)$ and used to transduce BMEC and bovine fibroblast cultures.

\section{BMEC transduction}

Primary cells were isolated from the mammary glands of Holstein cows (Bos taurus) in late pregnancy and cultured as previously described (Monzani et al., 2011). BMECs were cultivated on $60-\mathrm{mm}$ dishes to $30 \%$ confluence, when cells were transduced by incubation 
with $3 \mathrm{~mL}$ viral solution and $6 \mu \mathrm{g} / \mathrm{mL}$ hexadimethrine bromide. After 24-h incubation, the viral solutions were replaced by BMEC culture medium without antibiotics, and the cells were incubated for another $24 \mathrm{~h}$. Selection of transgenic cells was achieved by addition of 8 $\mu \mathrm{g} / \mathrm{mL}$ blasticidin into the culture medium for 20 days, with medium exchange every 3 days. The blasticidin concentration was previously optimized through the execution of a kill curve. The transgenes were confirmed by PCR amplification of the hFIX cDNA from genomic DNA. Promoter activity was assessed by mixing BMEC with random insertions of each promoter; BMEC were not isolated to evaluate the copy number of insertions.

\section{Induction of hFIX expression in mammary epithelial cells}

Transgenic and non-transgenic BMECs were cultured in induction medium (DMEM, 5\% fetal bovine serum (FBS), $84 \mu \mathrm{g} / \mathrm{mL}$ amikacin, $5 \mu \mathrm{g} / \mathrm{mL}$ prolactin, $5 \mu \mathrm{g} / \mathrm{mL}$ insulin, and $5 \mu \mathrm{g} / \mathrm{mL}$ hydrocortisone) for evaluation of gene expression and in culture medium (DMEM, 5\% FBS, 84 $\mu \mathrm{g} / \mathrm{mL}$ amikacin) for a negative control. All cultures were performed on extracellular matrix (5 $\mathrm{mg} / \mathrm{mL}$; Geltrex, Invitrogen) for 20 days. The culture medium was changed every 4 days. Culture media were frozen at $-20^{\circ} \mathrm{C}$ and used to analyze recombinant protein expression by Western blotting and coagulation activity. These experiments were performed in triplicate. At the end of the experiments, the cells were trypsinized; total RNA was extracted with the Trizol reagent and quantified by spectrophotometry at $260 \mathrm{~nm}$ (NanoDrop 2000, Thermo Scientific). cDNA synthesis was performed with $1 \mu \mathrm{g}$ RNA previously treated with DNase I, and the Impron II kit (Promega) according to manufacturer protocols. qPCR was used to evaluate the cDNA for relative expression of bovine glyceraldehyde-3-phosphate dehydrogenase (GAPDH), hFIX, and $\beta$-casein.

\section{Analysis of gene expression from different $\beta$-casein promoters}

The cDNAs from the induction and control experiments were used to quantify the relative expression of GAPDH, $\beta$-casein, and hFIX by qPCR (Applied Biosystems 7500 Real Time PCR System). Primers and probes are summarized in Table 2. Amplification reactions were performed in $1 \mathrm{X}$ TaqMan master mix (Applied Biosystems), $0.9 \mu \mathrm{M}$ of each primer and $0.25 \mu \mathrm{M}$ TaqMan probe in a final volume of $20 \mu \mathrm{L}$. The amplifications were performed with a first step of $50^{\circ} \mathrm{C}$ for $2 \mathrm{~min}$, a second step of $95^{\circ} \mathrm{C}$ for $10 \mathrm{~min}$, and a third step consisting of 50 cycles at $95^{\circ} \mathrm{C}$ for $15 \mathrm{~s}$ and $60^{\circ} \mathrm{C}$ for $1 \mathrm{~min}$. Differences in the frequencies of gene transcripts were calculated by the standard curve method using 5 serial 1:1 dilutions of sample cDNA(Livak and Schmittgen, 2001). Results are presented as arithmetic sample means and significant differences were evaluated (Duncan multiple range test).

\section{The effect of FBS on hFIX and $\beta$-casein expression}

Transgenic BMECs from Bos indicus with hFIX expression driven by $\mathrm{P} \beta$ cas 3 were used in triplicate experiments performed on extracellular matrix. One group of transgenic BMECs was cultured with 5\% FBS and another group with 5\% FBS and lactogenic hormones, as previously described (induction medium). The assays were carried out for 40 days, after which the culture medium was used for hFIX Western blotting and the cells were used for mRNA extraction, cDNA synthesis, and qPCR analysis of $\beta$-casein and hFIX. 
Table 2. Primers and probes used in the qPCR assays (Monzani et al., 2011).

\begin{tabular}{ll}
\hline & Sequence \\
\hline Primer & \\
$\beta$-casein - FWD & 5'-CCTCTTCCTCCAACTGTCATGTT-3' \\
$\beta$-casein - REV & 5'-AACAGGCAGGACTTTGGACTGA-3' \\
hFIX - FWD & 5'-GCAGCGCGTGAACATGATC-3' \\
hFIX - REV & 5'-TGAGTAGATATCCTAAAAGGCAGATGGT-3' \\
GAPDH - FWD & 5'-AAGGCCATCACCATCTTCCA-3' \\
GAPDH - REV & 5'-CCACTACATACTCAGCACCAGCAT-3' \\
Probe & 5'-FAM-CCTCCTCAGTCCGTGCTGTCCCTTT-TAMRA-3' \\
$\beta$-casein & 5'-FAM-TGGCAGAATCACCAGGCCTCAT-TAMRA-3' \\
hFIX & 5'-VIC-AGCGAGATCCTGCCAACATCAAGTGGT-3' \\
GAPDH & \\
\hline
\end{tabular}

\section{Production of transgenic embryos and transgene analysis}

Lentivirus carrying the $\mathrm{P} \beta$ cas5 promoter was used to transduce bovine fibroblasts from a female with phenotypically high blastocyst production, previously known in our laboratory. The transgenic cells obtained after selection with $5 \mu \mathrm{g} / \mathrm{mL}$ blasticidin were used as nuclear donors for SCNT, which was performed as previously described (Miranda et al., 2009). Genomic DNA and mRNA from the transgenic fibroblasts were used for transgene analysis of hFIX by PCR and analysis of hFIX expression by qPCR in cells cultured on plastic with culture medium (DMEM, 10\% FBS, $84 \mu \mathrm{g} / \mathrm{mL}$ amikacin).

Five individual transgenic blastocysts were assessed for presence of the hFIX transgene. The embryos were lysed in $5 \mu \mathrm{L}$ lysis buffer containing $1 \mathrm{X}$ Taq buffer, $0.5 \mathrm{mg} / \mathrm{mL}$ proteinase $\mathrm{K}$, and $1.25 \%$ Triton $\mathrm{X}-100$. The samples were lysed at $55^{\circ} \mathrm{C}$ for $30 \mathrm{~min}$ and the proteinase was inactivated at $95^{\circ} \mathrm{C}$ for $5 \mathrm{~min}$. Samples were centrifuged at $1200 \mathrm{~g}$ for $5 \mathrm{~min}$ and the supernatant was used as a template for PCR, using the same conditions and cycling for hFIX cDNA amplification. A pool of 5 transgenic embryos was used for mRNA extraction and qPCR evaluation of hFIX expression. A pool of 6 parthenogenetic blastocysts was used as a PCR control.

\section{Embryo transfer, pregnancy monitoring, and transgenic birth}

One or two embryos at the blastocyst stage on day 7 after reconstruction were placed on 0.25 -mL straws containing buffered SOF medium and transferred non-surgically to 21 synchronized recipients. Pregnancy diagnoses were performed by transrectal ultrasonography (Aloka SSD-900, Aloka Co.) on days 30,75, and 120. Two transgenic animals were obtained, and the transgene was evaluated by PCR.

\section{RESULTS AND DISCUSSION}

\section{Construction of vectors and transgenic BMECs}

The strategy for amplification and cloning of the $\beta$-casein promoter was successful. After obtaining the $\mathrm{P} \beta$ cas 5 fragment, the sequence of the proximal region was verified, while the distal region was not sequenced. However, the primers used to amplify $\mathrm{P} \beta$ cas 4 and $\mathrm{P} \beta$ cas 3 were targeted to the distal region. The resultant amplicons were the expected sizes, suggesting 
the entire sequence of the $\beta$-casein promoter used in the vector constructs was correct. Figure $1 \mathrm{~A}$ shows the restriction map of the expression vectors. Different sizes of the bovine $\beta$-casein promoter have been used to drive recombinant protein expression in the milk of transgenic animals. Naruse and collaborators used $1.8-\mathrm{kb}$ and $3.1-\mathrm{kb}$ fragments of the $\beta$-casein promoter with the untranslated first exon of the $\beta$-casein gene and the poly-A signal of bovine growth hormone. They observed low expression from the $1.8 \mathrm{-kb}$ promoter and suggested the $3.1-\mathrm{kb}$ promoter can be used to induce mammary gland-specific expression of transgenes in transgenic animals (Naruse et al., 2006). Other authors (Sohn et al., 1999, 2003) have used a 10-kb fragment including untranslated exon 1 , intron 1 , and the 5'-UTR of exon 2 . The use of the entire $\beta$-casein promoter, including exon 1 and exon 2, may be ideal for recombinant protein expression in milk; however, the best system to integrate exogenous DNA into active transcription units of the genome is currently thought to be the lentiviral system. The advantages and disadvantages of lentiviral transgenic approaches have been reviewed (Park, 2007). The use of large promoters can prevent packaging of the lentiviral genetic material and its production. In this study, 3 different sizes of the bovine $\beta$-casein promoter, including the untranslated first exon and partial intron 1 (218-bp), were evaluated. A similar construct was used previously (Kim et al., 1994), with $2 \mathrm{~kb}$ of the bovine $\beta$-casein promoter containing the untranslated exon 1 plus $170 \mathrm{bp}$ of intron 1 . All of the constructs produced viral particles that were used to transduce BMECs; the largest construct was approximately $13 \mathrm{~kb}$, which includes the $9.5-\mathrm{kb}$ to be packaged as vector.

BMECs were isolated from the mammary gland of a pregnant $B$. taurus and analyzed for their capacity to differentiate into alveoli-like structures and $\beta$-casein expression (Monzani et al., 2011). These cells were used for lentiviral transduction; transgenic cells were selected by antibiotic resistance and hFIX transgene presence was verified by PCR (Figure 1B).

\section{hFIX expression in BMECs}

Mammary epithelial cell cultures have been proposed as an alternative approach to reproduce the biology of the mammary gland (Rose and McConochie, 2006); therefore, BMEC culture may become an important system to evaluate recombinant protein expression. Expression of hFIX driven by 3 bovine $\beta$-casein promoters was evaluated in transgenic BMECs cultured on extracellular matrix and induction medium. Negative controls included BMECs in culture medium. Relative quantification by qPCR revealed 6-fold greater expression of hFIX from $\mathrm{P} \beta$ cas 5 than from $\mathrm{P} \beta$ cas 3 and $\mathrm{P} \beta$ cas 4 , between which there was no significant difference (Figure 2A). Statistical analysis revealed no significant difference between the induced and control assays (Figure 2A), probably because BMECs isolated from pregnant $B$. taurus have lost the capacity to express $\beta$-casein. Gene expression analysis by qPCR detected only the endogenous gene (GAPDH) and hFIX cDNA, and $\beta$-casein expression was not detected. Isolation and selection of transgenic BMECs were performed on plastic, although previous studies have reported that culture of BMECs on plastic prevents the synthesis of milk components within a few days (Larson, 1976; Blum et al., 1989). Another group reported the expression of milk proteins in BMECs cultured on plastic; however, they observed a gradual decrease in synthesis upon repeated in vitro passage and the ability to synthesize milk proteins almost completely disappeared after a long period of in vitro culture (Ahn et al., 1995). The loss of $\beta$-casein expression by transgenic BMECs could be due to silencing of the milk protein genes; 


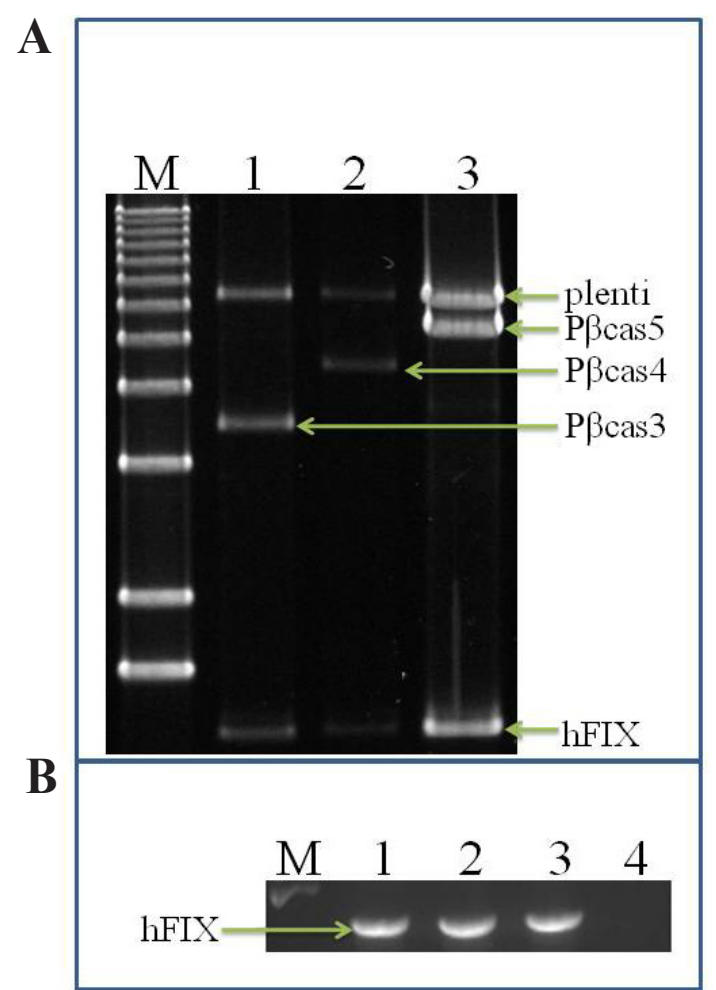

Figure 1. A. Restriction mapping of the expression vectors constructed. The 6.4-kb fragment corresponds to the fragment of the vector pLenti-6.2-GW/EmGFP without the PCMV promoter and the reporter gene EmGFP. The 1.4-kb fragment corresponds to the human coagulation factor IX (hFIX) cDNA. Lane $M=$ molecular weight marker 1 -kb plus (Invitrogen); lanes 1 to $3=$ fragments from $\beta$-casein promoter; lane $1=\mathrm{pLenti6.2-P} \beta \operatorname{cas} 3 / \mathrm{hFIX}$ (3.3-kb fragment); lane 2 = pLenti-6.2-P $\beta$ cas $4 / \mathrm{hFIX}$ (4.2-kb fragment); lane 3 = pLenti-6.2-P $\beta$ cas $5 / \mathrm{hFIX}$ (5.3$\mathrm{kb}$ fragment). B. Analysis of the transgene in the bovine mammary epithelial cells (BMECs) by PCR. Lane $M=$ molecular weight marker 1-kb plus (Invitrogen); lanes 1 to $3=1.3-\mathrm{kb}$ fragments of hFIX from BMECs transduced with the 3 different constructs, pLenti6.2-P $\beta$ cas3/hFIX, pLenti6.2-P $\beta$ cas $4 / \mathrm{hFIX}$, and $\mathrm{pLenti6.2-P} \beta$ cas $5 / \mathrm{hFIX}$, respectively; lane $4=$ non-transformed BMECs.

however, the same lack of expression was not observed for hFIX cDNA expression driven by the exogenous $\beta$-casein promoter. This observation suggests that the mechanism regulating endogenous gene silencing, mediated by plastic culture, relies on the $\beta$-casein promoter before BMEC modification. This hypothesis is corroborated by the fact that $\beta$-casein expression was not detected in untransformed BMECs (Monzani et al., 2011) and therefore, the silencing had no effect on the exogenous promoter. It has been reported that FBS is able to induce $\alpha$-casein expression (Rose and McConochie, 2006) in lesser amounts than FBS with lactogenic hormones. There was no significant difference between the induced and control experiments, and it is possible that not all of the cells are responding to the lactogenic hormones, implying that hFIX expression is influenced by FBS. Although $\beta$-casein was not expressed, the experiment points to $\mathrm{P} \beta$ cas 5 as the best promoter among the fragments studied. We used fragments of approximately $3.3,4.2$, and $5.3 \mathrm{~kb}$, with approximately 6 -fold greater expression from the latter. 
This result suggests that the $\mathrm{P} \beta$ cas 5 fragment more efficiently expresses recombinant proteins, and its use for the production of transgenic animals may be preferred over the previously suggested 3.1-kb (Naruse et al., 2006) and 3.8-kb (Cerdan et al., 1998) promoters. Expression of hFIX was verified by whole mRNA from the cDNA of transgenic BMECs by PCR (Figure 2B). In this analysis, a mix of cDNA from 3 samples of the induction assays was used. The same amount of mRNA was used for cDNA production, of cDNA for PCR amplification of hFIX, and of samples applied in the gel - the results showed the highest expression of hFIX was driven by $\mathrm{P} \beta \mathrm{cas} 5$, followed by an intermediate level of expression driven by $\mathrm{P} \beta$ cas 4 , and the least expression driven by $\mathrm{P} \beta$ cas3 (Figure 2B). This result suggests that $\mathrm{P} \beta$ cas 4 is a stronger promoter than $\mathrm{P} \beta$ cas3, although no significant differences in hFIX expression were observed in the qPCR assays of $\mathrm{P} \beta$ cas 4 and $\mathrm{P} \beta$ cas 3 . In Western blots, the recombinant protein was not detected in the culture medium or extract from the alveolus-like structures, possibly due to the low level of hFIX cDNA expression. For the strongest promoter, approximately 215-fold less expression was observed for hFIX than for the endogenous gene (GAPDH). The low expression may be related to the fact that the cells do not respond to lactogenic hormones. mRNA stability in cell cultures also can influence Western blotting. It has been reported that intron 1 of the hFIX mRNA is important for stability (Zheng et al., 1997). In our constructs, the hFIX cDNA sequence was used without introns, which may reduce mRNA stability in BMEC culture. Other groups have used a poly-A signal from growth hormone (Naruse et al., 2006) or the cloned gene (Schnieke et al., 1997). We used the poly-A signal located in the "R" region of the 3'-LTR of the lentiviral vector. Instability of the mRNA, combined with low hFIX cDNA expression, may make it difficult to detect recombinant protein.

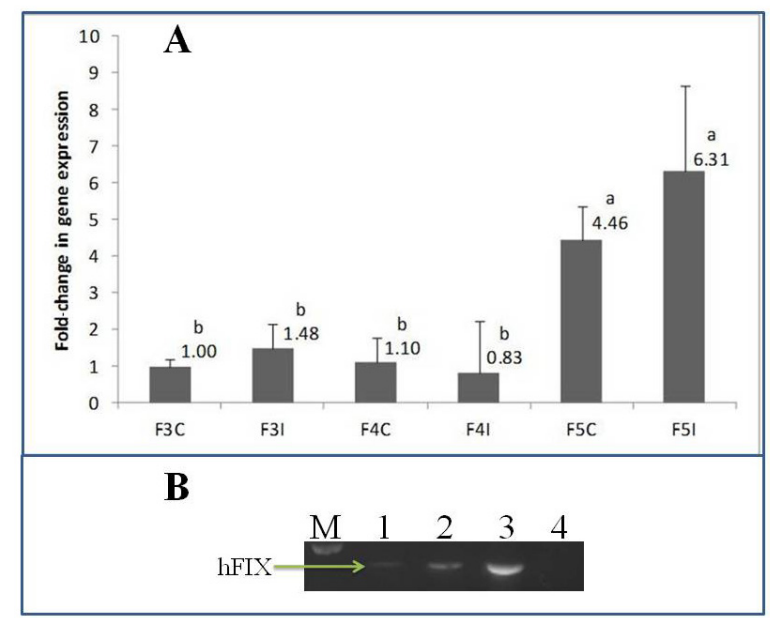

Figure 2. A. Relative quantification of the human coagulation factor IX (hFIX) expression by qPCR driven by 3 fragments of the $\beta$-casein promoter in the bovine mammary epithelial cell (BMEC) culture from Bos taurus. F3 = BMECs transformed with pLenti6.2-P $\beta$ cas3/hFIX; F4 = BMECs transformed with pLenti6.2-P $\beta$ cas4/hFIX; $\mathrm{F} 5=$ BMECs transformed with pLenti6.2-P $\beta$ cas $5 / \mathrm{hFIX} ; \mathrm{C}=$ assay using $5 \%$ fetal bovine serum (FBS) (control); $\mathrm{I}=$ assay using $5 \%$ FBS plus lactogenic hormones (induction). Means with the same letter are not significantly different $(\mathrm{N}=3)$. B. Analysis of hFIX cDNA expression by RT-PCR from the cDNA of induced BMECs. Lane $M=$ molecular weight marker $1-\mathrm{kb}$ plus (Invitrogen); lanes 1 to $3=1.3-\mathrm{kb}$ fragments of the hFIX cDNA from BMECs transduced with pLenti6.2-P $\beta$ cas3/hFIX, pLenti6.2-P $\beta$ cas $4 / \mathrm{hFIX}$, and pLenti6.2-P $\beta$ cas $5 / \mathrm{hFIX}$, respectively; lane $4=$ non-transformed BMECs. 
Recombinant hFIX was not identified in Western blotting, in either the culture medium or the cellular extract, or by coagulation activity assays (data not shown). These results must be due to the low expression of hFIX, which renders identification of the recombinant protein more difficult.

\section{Influence of FBS on $\beta$-casein and hFIX expression}

qPCR in the control and induced samples of B. taurus BMECs showed that promoter $\mathrm{P} \beta$ cas 5 was optimal for hFIX expression, but the cells had lost the capacity for milk protein expression. In this assay, we verified that FBS in the culture medium induces $\beta$-casein expression, as was reported for induction of $\alpha$-casein (Rose and McConochie, 2006). In this experiment, BMECs from $B$. indicus that showed $\beta$-casein expression cultured in vitro (Monzani et al., 2011) were isolated and transduced with lentivirus containing the $\mathrm{P} \beta \mathrm{cas} 3$ promoter. This relatively weak promoter was used to evaluate its capacity to respond to induction by lactogenic hormones relative to the endogenous $\beta$-casein promoter. FBS was used as a control to verify that FBS contains elements able to induce $\beta$-casein expression as proposed (Rose and McConochie, 2006). $\beta$-casein was expressed approximately 490 -fold more by using lactogenic hormones than FBS (Figure 3). Thus, these cells were able to respond to induction by lactogenic hormones. The low $\beta$-casein expression with FBS suggests that basal $\beta$-casein expression may be due to possible inductor molecules present in the FBS. Another possibility is that expression is being influenced by the extracellular matrix, causing basal induction (Schmidhauser et al., 1990). qPCR analysis of hFIX expression from the P $\beta$ cas 3 promoter in BMEC from $B$. indicus showed an 8-fold increase in expression with lactogenic hormones versus cells cultured in FBS alone. Either $\mathrm{P} \beta$ cas 3 lacks regulatory elements that respond to lactogenic hormones for complete induction or the response can be influenced by localization of the insertion in the genome. The qPCR analysis, based on the differences in the CT values, showed that the expression of $\beta$-casein (mean $\mathrm{CT}=32.85$ ) in the induced cells was 6 -fold greater than the expression of hFIX (mean of CT $=35.40$ ) in the induced cells driven by the $\mathrm{P} \beta$ cas 3 promoter. A similar difference was observed between hFIX expression driven by $\mathrm{P} \beta$ cas 5 and $\mathrm{P} \beta$ cas 3 in BMEC from $B$. taurus, with approximately 6-fold more from P $\beta$ cas5, as shown in the Figure $2 \mathrm{~A}$. Thus, $\mathrm{P} \beta$ cas 5 contains almost all of the regulatory elements necessary for expression of $\beta$-casein and must be as efficient as the entire $\beta$-casein promoter. This promoter may be an efficient means to promote high expression in milk.

\section{Production of transgenic embryos and animals}

Isolation and transformation of the BMECs required various passages in culture, and it has been proposed that the cultivation of cells for long periods commits them for use in cloning (Kubota et al., 2000). Therefore, fibroblasts from a known cow with phenotypically good embryo production were transformed with the $\mathrm{P} \beta$ cas 5 promoter construct and used for embryo production. Five individual embryos were used for PCR analysis of the transgene, using primers $\mathrm{P} 7$ and $\mathrm{P} 8$ for hFIX cDNA, embryo gDNA as template, and gDNA from a pool of parthenogenetic embryos as a control. The results confirmed that the embryos were transgenic (Figure 4A). The use of transgenic cells for cloning did not influence the rate of blastocysts obtained in the cloning step versus cells that were not transformed (Table 3). An approximately 


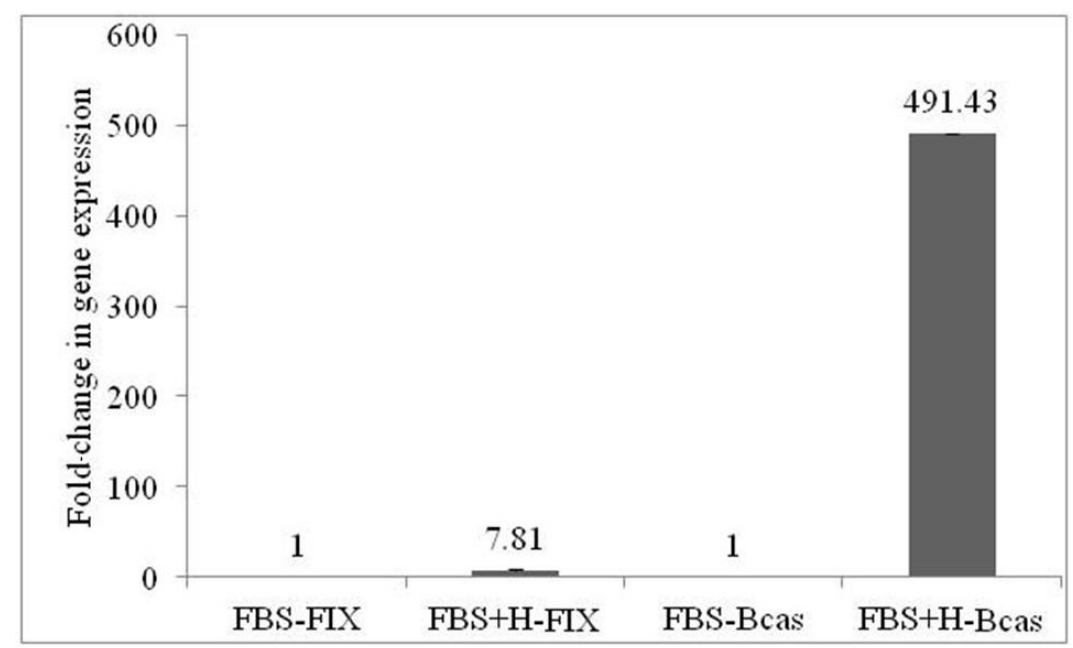

Figure 3. Relative quantification of the expression of human coagulation factor IX (hFIX) and $\beta$-casein using bovine mammary epithelial cells from Bos indicus that showed $\beta$-casein expression cultured in vitro. FBS-FIX $=$ relative expression of the hFIX cDNA using $5 \%$ fetal bovine serum (FBS); FBS + H-FIX $=$ relative expression of hFIX using 5\% FBS plus lactogenic hormones. Approximately an 8-fold increase in the expression compared with the control was observed; FBS-Bcas $=$ relative expression of $\beta$-casein using $5 \% \mathrm{FBS}$; FBS $+\mathrm{H}$-Bcas $=$ relative expression of $\beta$-casein using 5\% FBS plus lactogenic hormones. A 490 times increase in the expression compared with the control was observed.

$28 \%$ yield of blastocysts was obtained, which is consistent with reports of approximately 25 to $35 \%$ for non-modified cells, and in comparison to controls from the same cow reported in our laboratory (Table 3 ). This suggests that the modification did not interfere with blastocyst production. For implantation of the embryos, 21 receptor cows were synchronized and embryos transferred, with some cows receiving 2 embryos that had not hatched. At 30 days, 8 receptor cows were pregnant, and only 2 animals were pregnant at 75 and 120 days (Table 3 ). An ultrasound of the pregnancy at 120 days is shown in Figure 4B. The use of SCNT with transgenic cells may be an important tool for the production of transgenic animals. If this technique uses previously selected transgenic cell as nuclear donors, production of a transgenic animal is ensured (Brink et al., 2000), whereas the use of other techniques, such as nuclear microinjection, does not ensure that the animal produced will be transgenic and imposes a long waiting period (until the birth of the animal) before the transgene can be analyzed. The use of SCNT guarantees the presence of the transgene, but does not guarantee that the recombinant protein will be expressed. Various factors can be influence expression, such as exogenous DNA localization in the genome and epigenetic events that occur in the reprogramming during blastocyst development. The use of an isolated transgenic cell is ideal, with verified localization of the exogenous DNA and the capacity to express the recombinant protein. However, this analysis requires various passages that prevent use of the cells for SCNT. Indeed, the production of the recombinant protein in milk can be evaluated only with induction of lactation in the adult transgenic animal. However, the use of mammary epithelial cells must be an interesting model for analysis of the efficiency of transgene constructs. 


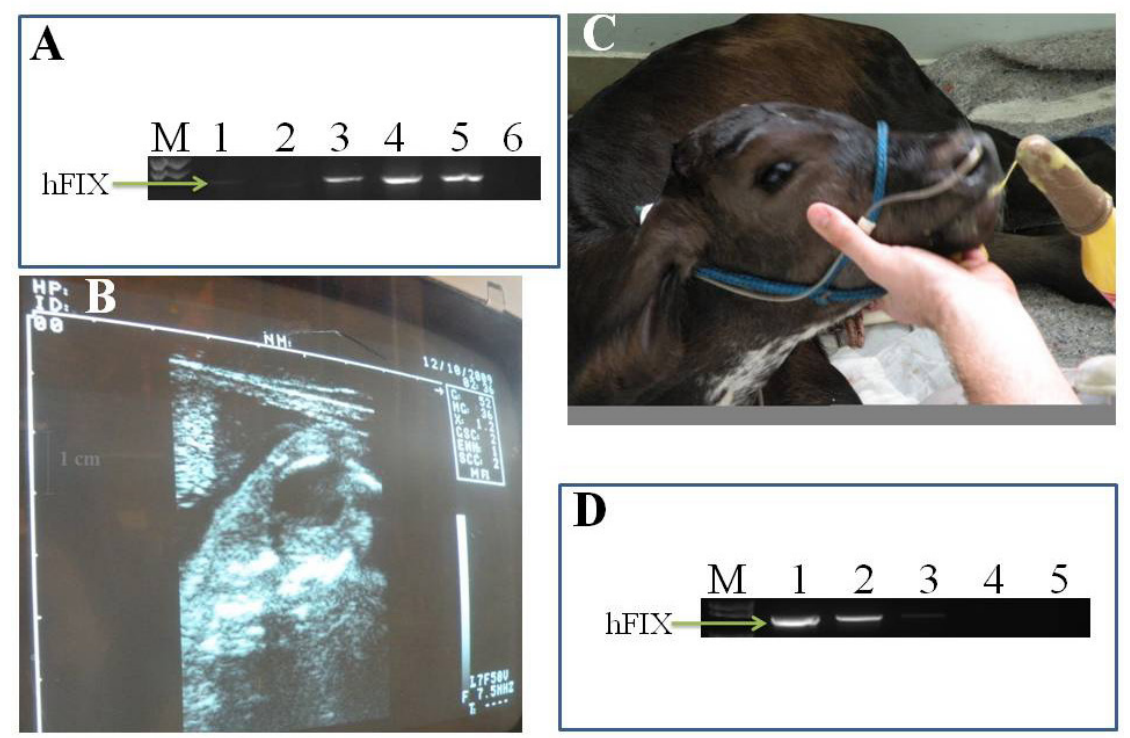

Figure 4. A. Analysis of the transgene in the embryos by PCR. Lane $M=$ molecular weight marker 1-kb plus (Invitrogen); lanes 1 to 5 = individual transgenic embryos showing the $1.3-\mathrm{kb}$ fragment of the human coagulation factor IX (hFIX) cDNA; lane $6=$ parthenogenetic embryos used as a negative control. B. Ultrasound image from transgenic fetus at 120 days of pregnancy. The head and eye of the fetus can be observed in the image. C. Transgenic bovine 1. D. Analysis of the transgene in the born cattle. Lane $M=$ molecular weight marker 1-kb plus (Invitrogen); lane $1=$ the constructed vector pLenti6.2-P $\beta$ cas $5 / \mathrm{hFIX}$; lane $2=$ transgenic bovine 1 ; lane 3 = transgenic bovine 2; lane $4=$ cow cell donor for transgene; lane $5=$ cow receptor. Amplification was obtained only in the positive control pLenti6.2-P $\beta$ cas $5 / \mathrm{hFIX}$ and in the transgenic cattle.

Table 3. Cloning steps (Monzani et al., 2011).

\begin{tabular}{lccccccc}
\hline Group & Oocytes & 1st PB extrusion & Reconstructed & Fusion & Blastocysts & Receptors & Pregnancy (120 days) \\
& $\mathrm{N}$ & $\mathrm{N}(\%)$ & $\mathrm{N}$ & $\mathrm{N}(\%)$ & $\mathrm{N}(\%)$ & $\mathrm{N}$ & $\mathrm{N}$ \\
\hline Transgenic & 577 & $371(64.3)$ & 237 & $183(77.2)$ & $52(28.4)$ & 21 & 2 \\
Control & 1109 & $677(61.0)$ & 418 & $313(74.8)$ & $89(28.4)$ & 17 & 1 \\
\hline
\end{tabular}

Expression of hFIX in transformed fibroblasts and isolated embryos was analyzed by qPCR, which showed that fibroblasts cultured on plastic exhibit low expression in comparison to BMECs, while expression in the embryos was not detected. The BMECs showed hFIX expression of approximately 215 -fold less than the GAPDH gene; in the fibroblasts, hFIX expression was approximately 400 -fold less than that of the endogenous gene, based on the difference in $\mathrm{CT}$ values and using the strongest promoter. These results suggest FBS may act at the promoter to induce hFIX expression or these cells do not represent a negative control to block basal promoter expression. The fact that the transgenic BMECs from B. taurus did not express $\beta$-casein but did express hFIX may indicate these cells have lost the ability to express milk protein after being isolated and selected on plastic culture. Thus, silencing of milk protein genes must occur before exogenous gene insertion or the exogenous $\beta$-casein promoter was not silenced due to insertion into the genome. However, these cells did not 
respond to lactogenic hormone induction, as the control and induced assays did not show any significant difference in expression (Figure 2A). The mechanisms of the lactogenic hormone signaling cascade stimulated must be blocked. In the BMECs from $B$. indicus that were able to express $\beta$-casein (Monzani et al., 2011), both $\beta$-casein and hFIX were inducible by lactogenic hormones, suggesting that the $\mathrm{P} \beta$ cas 3 promoter contains some, but not all, of the regulatory elements that respond to lactogenic hormones. The lower hFIX expression observed in the modified fibroblasts suggests that non-tissue-specific expression was probably obtained due to basal expression of the promoter and the absence of a negative control. During embryonic development, the mechanism of reprogramming must act upon the exogenous promoter, explaining why hFIX expression was not obtained in the embryos. The exogenous promoter was likely reprogrammed to drive tissue-specific expression. Although recombinant hFIX was not detected efficiently, the analysis of modified BMECs in vitro might be an effective model for transgene evaluation, principally if the BMECs continue to express milk protein after isolation and transduction.

Two transgenic animals were obtained (Figure 4C), but they died after birth due to intrinsic problems of cloning. PCR analysis showed the animals were transgenic (Figure 4D). Cells from the animals were cultured and frozen, and they will be used for re-cloning.

In conclusion, the $\mathrm{P} \beta$ cas 5 promoter showed the highest capacity for hFIX cDNA expression in genetically modified BMECs, in comparison with the P $\beta$ cas 3 and P $\beta$ cas 4 promoters; therefore, it was more efficient and should be used to optimize transgenic animal production for recombinant protein expression. hFIX expression in BMECs without the capacity to express $\beta$-casein showed some independence from the influence of lactogenic hormones and the recombinant protein could not be detected, but expression driven by different promoters could be evaluated by qPCR. However, in BMECs able to express milk protein, induction of the exogenous promoter by lactogenic hormones may permit efficient evaluation of the capacity for gene expression of different constructs. In vitro analysis of BMECs can be an important tool for evaluating transgene expression and may be used as a preliminary step for transgenic animal production. Transgenic cells were obtained through lentivirus transduction and used in SCNT. Although the cloned transgenic calves died at birth, the combination of these techniques may be an efficient strategy for generation of transgenic cattle.

\section{ACKNOWLEDGMENTS}

Research supported by FAPESP. P.S. Monzani was the recipient of a FAPESP postdoctoral fellowship.

\section{REFERENCES}

Ahn JY, Aoki N, Adachi T, Mizuno Y, et al. (1995). Isolation and culture of bovine mammary epithelial cells and establishment of gene transfection conditions in the cells. Biosci. Biotechnol. Biochem. 59: 59-64.

Balland A, Faure T, Carvallo D, Cordier P, et al. (1988). Characterisation of two differently processed forms of human recombinant factor IX synthesised in CHO cells transformed with a polycistronic vector. Eur. J. Biochem. 172: 565572.

Bishop P and Lawson J (2004). Recombinant biologics for treatment of bleeding disorders. Nat. Rev. Drug Discov. 3: 684-694.

Blum JL, Zeigler ME and Wicha MS (1989). Regulation of mammary differentiation by the extracellular matrix. Environ. Health Perspect. 80: 71-83. 
Bond M, Jankowski M, Patel H, Karnik S, et al. (1998). Biochemical characterization of recombinant factor IX. Semin. Hematol. 35: 11-17.

Brink MF, Bishop MD and Pieper FR (2000). Developing efficient strategies for the generation of transgenic cattle which produce biopharmaceuticals in milk. Theriogenology 53: 139-148.

Cerdan MG, Young JI, Zino E, Falzone TL, et al. (1998). Accurate spatial and temporal transgene expression driven by a 3.8-kilobase promoter of the bovine $\beta$-casein gene in the lactating mouse mammary gland. Mol. Reprod. Dev. 49: 236-245.

Fernlund P and Stenflo J (1983). Beta-hydroxyaspartic acid in vitamin K-dependent proteins. J. Biol. Chem. 258: 1250912512 .

Houdebine LM (2000). Transgenic animal bioreactors. Transgenic Res. 9: 305-320.

Houdebine LM (2009). Production of pharmaceutical proteins by transgenic animals. Comp. Immunol. Microbiol. Infect. Dis. 32: 107-121.

Kim SJ, Cho YY, Lee KW, Yu DY, et al. (1994). Expression of human lactoferrin in milk of transgenic mice using bovine $\beta$-casein/human lactoferrin cDNA fusion gene. Mol. Cells 4: 355-360.

Kim MO, Kim SH, Lee SR, Shin MJ, et al. (2007). Ectopic expression of tethered human follicle-stimulating hormone (hFSH) gene in transgenic mice. Transgenic Res. 16: 65-75.

Kubota C, Yamakuchi H, Todoroki J, Mizoshita K, et al. (2000). Six cloned calves produced from adult fibroblast cells after long-term culture. Proc. Natl. Acad. Sci. U. S. A. 97: 990-995.

Kurachi K and Davie EW (1982). Isolation and characterization of a cDNA coding for human factor IX. Proc. Natl. Acad. Sci. U. S. A. 79: 6461-6464.

Larson BL (1976). Comparative production of beta-lactoglobulin and orotic acid with lactose in bovine mammary cell cultures: effects of cell density and constituent inhibition. J. Dairy Sci. 59: 1881-1889.

Livak KJ and Schmittgen TD (2001). Analysis of relative gene expression data using real-time quantitative PCR and the $2^{-\Delta \Delta C T}$ method. Methods 25: 402-408.

Miranda MS, Bressan FF, Zecchin KG, Vercesi AE, et al. (2009). Serum-starved apoptotic fibroblasts reduce blastocyst production but enable development to term after SCNT in cattle. Cloning Stem Cells 11: 565-573.

Monzani PS, Bressan FF, Mesquita LG, Sangalli JR, et al. (2011). $\beta$-casein gene expression by in vitro cultured bovine mammary epithelial cells derived from developing mammary glands. Genet. Mol. Res. 10: 604-614.

Naruse K, Yoo SK, Kim SM, Choi YJ, et al. (2006). Analysis of tissue-specific expression of human type II collagen cDNA driven by different sizes of the upstream region of the $\beta$-casein promoter. Biosci. Biotechnol. Biochem. 70 : 93-98.

Niemann H and Kues WA (2007). Transgenic farm animals: an update. Reprod. Fertil. Dev. 19: 762-770.

Park F (2007). Lentiviral vectors: are they the future of animal transgenesis? Physiol. Genomics 31: 159-173.

Raught B, Liao WS and Rosen JM (1995). Developmentally and hormonally regulated CCAAT/enhancer-binding protein isoforms influence $\beta$-casein gene expression. Mol. Endocrinol. 9: 1223-1232.

Rose MT and McConochie H (2006). The long road to a representative in vitro model of bovine lactation. JIFS 3: 67-72.

Rudolph NS (1999). Biopharmaceutical production in transgenic livestock. Trends Biotechnol. 17: 367-374.

Schmidhauser C, Bissell MJ, Myers CA and Casperson GF (1990). Extracellular matrix and hormones transcriptionally regulate bovine $\beta$-casein 5 ' sequences in stably transfected mouse mammary cells. Proc. Natl. Acad. Sci. U. S. A. 87: 9118-9122.

Schnieke AE, Kind AJ, Ritchie WA, Mycock K, et al. (1997). Human factor IX transgenic sheep produced by transfer of nuclei from transfected fetal fibroblasts. Science 278: 2130-2133.

Sohn BH, Kim SJ, Park H, Park SK, et al. (1999). Expression and characterization of bioactive human thrombopoietin in the milk of transgenic mice. DNA Cell Biol. 18: 845-852.

Sohn BH, Chang HG, Kang HS, Yoon H, et al. (2003). High level expression of the bioactive human interleukin-10 in milk of transgenic mice. J. Biotechnol. 103: 11-19.

Suttie JW (1980). Mechanism of action of vitamin K: synthesis of gamma-carboxyglutamic acid. CRC Crit. Rev. Biochem. 8: 191-223.

White GC, Beebe A and Nielsen B (1997). Recombinant factor IX. Thromb. Haemost. 78: 261-265.

Zheng B, Qiu XY, Tan M, Xing YN, et al. (1997). Increment of hFIX expression with endogenous intron 1 in vitro. Cell Res. 7: 21-29. 